\title{
Análise temporal de focos de calor na reserva da biosfera da Serra do Espinhaço
}

\author{
Eduarda Soares MENEZES ${ }^{1 *}$, Danielle Piuzana MUCIDA ${ }^{1}$, Luciano Cavalcante de Jesus FRANÇA², \\ Marcos Vinicius Miranda AGUILAR ${ }^{3}$, Israel Marinho PEREIRA ${ }^{1}$
}

\begin{abstract}
${ }^{1}$ Programa de Pós-Graduação em Ciência Florestal, Universidade Federal dos Vales do Jequitinhonha e Mucuri, Diamantina, MG, Brasil.
${ }^{2}$ Programa de Pós-Graduação em Engenharia Florestal, Universidade Federal de Lavras, Lavras, MG, Brasil.

${ }^{3}$ Departamento de Engenharia Florestal, Instituto Federal do Norte de Minas Gerais, Salinas, MG, Brasil. E-mail: duda.engflorestal@gmail.com
\end{abstract}

Recebido em junho/2018; Aceito em dezembro/2018.

\begin{abstract}
RESUMO: O estudo teve como objetivo avaliar o método de densidade de Kernel na modelagem espacial e temporal de focos de calor em unidades de conservação de proteção integral inseridos em área da Reserva da Biosfera da Serra do Espinhaço. Foram analisadas imagens vetoriais referentes aos anos de 2000, 2005, 2010, 2015 e 2017 processadas no software QGIS 2.18.16, a partir da sobreposição das mesmas com os registros de focos de calor. A densidade dos focos foi calculada por meio do estimador de Kernel com classificação dos focos em níveis: muito baixa, baixa, média, alta e muito alta. Demonstrou-se a representação dos focos de calor para os anos citados e sua relação à concentração de riscos de incêndios em áreas que compõem a RBSE, levando a percepção das simulações ao longo dos anos, corroborando com os registros de incêndios florestais. A estimativa realizada pela função de Densidade de Kernel apresentou a capacidade de indicar a distribuição e intensidade dos focos, constituindo uma potencial ferramenta para norteamento de atividades de prevenção e fiscalização.
\end{abstract}

Palavras-chave: densidade de Kernel, geoprocessamento, incêndios florestais, monitoramento ambiental.

\section{Temporal analysis of heat foci at Espinhaço Range biosphere reserve}

\begin{abstract}
The object of this paper was to evaluate the use of the Kernel density method in the spatial and temporal analysis of heat foci in integral protection conservation units of the Espinhaço Range Biosphere Reserve. For that, vector images of the years 2000, 2005, 2010, 2015 and 2017 were analyzed and processing was performed by QGIS software 2.18.16, from the overlapping of these with the records of heat sources. The heat foci density was calculated using the Kernel estimator and five levels of classification were used: very low, low, medium, high and very high. It was demonstrated the heat sources representation for the cited years and their relation to the concentration of fire risks in areas of the RBSE, leading to the perception of the simulations over the years, corroborating with forest fire records. The Kernel Density estimation showed the ability to indicate the distribution and intensity of the foci, constituting an interesting tool to guide prevention and surveillance activities.
\end{abstract}

Keywords: Kernel density, geoprocessing, forest fires, environmental monitoring.

\section{INTRODUÇÃO}

A ocorrência de incêndios florestais, seja de origem antrópica ou natural, pode provocar modificações na estrutura e no padrão do processo produtivo florestal. Alterações no regime de fogo dos ecossistemas podem resultar na redução das interações no ecossistema, destruição da riqueza genética de populações, fragmentação dos habitats e por afetar a comunidade de forma direta ou indireta em virtude dos recursos e benefícios proporcionados pelo ambiente (RIBEIRO et al., 2012).

No Brasil, nota-se que grande parte das Unidades de Conservação são atingidas, ao longo dos anos, por incêndios florestais. Dessa forma, o fogo pode ser considerado como uma grande ameaça à conservação da biodiversidade e aos processos ecológicos nas áreas naturais (TEBALDI et al., 2013). Ainda que o fogo seja considerado como parte da ecologia do Cerrado, pesquisas evidenciam que o aumento da ocorrência de incêndios provoca alteração na estrutura da vegetação, favorece o aparecimento de plantas herbáceas, diminui a diversidade de espécies, além de alterar processos evolutivos do bioma provocando a degradação dos solos (MACHADO NETO et al., 2017).

Uma grande concentração de unidades de conservação no estado de Minas Gerais ocorre na Reserva da Biosfera da Serra do Espinhaço (RBSE). Seu território é relevante no tocante aos recursos hídricos, abarcando parte de grandes bacias hidrográficas federais, além de possuir exuberantes formações geológicas e florísticas (PEREIRA et al., 2015). Em sua complexidade, apresenta diversos organismos que se desenvolvem apenas nessa área, contribuindo para reforçar a necessidade de sua preservação e conservação. Entretanto, uma das ameaças contínuas que colocam a sustentabilidade $\mathrm{e}$ conservação da reserva em risco é a ocorrência de incêndios florestais nos biomas que a abarcam, representando um dos principais fatores de degradação das unidades de conservação existentes em seu território.

Nesse contexto, para auxiliar na determinação de medidas de controle e prevenção, torna-se necessário reconhecer o perfil dos incêndios florestais, normalmente pelo uso de ferramentas estatísticas (RODRÍGUEZ et al., 2013). Neste 
sentido, estudos relacionados com a incidência de focos de calor pelo uso de Sistema de Informações Geográficas (SIG), em conjunto com técnicas de variáveis do geoprocessamento servem como alternativa metodológica para o monitoramento a partir de mapas manipulados e interligados aos focos presentes em uma região de interesse. Além disso, podem auxiliar em medidas preventivas como por exemplo, implementação de planos de manejo, gestão de unidade de conservação e planejamento, de forma estratégica, de práticas de prevenção a longo prazo (TORRES et al. 2014; TORRES et al., 2017).

No Brasil, o monitoramento de queimadas por meio de imagens de satélites é indispensável, uma vez que meios intensivos de acompanhamento são difíceis dada as condições territoriais e de logística. Assim, imagens podem ser utilizadas em interpretações da evolução do uso/ocupação da cobertura vegetal, permitindo a identificação nos padrões de mudança, tanto quantitativa, quanto qualitativa ao longo do tempo (MORAIS et al., 2016) e, mais especificamente, proporcionando melhor compreensão da relação fogo e clima (VIJAYAKUMAR et al., 2015).

Diante do exposto, o presente trabalho teve como objetivo avaliar o uso do método da densidade de Kernel na análise espacial e temporal de focos de calor em unidades de conservação de proteção integral presentes na Reserva da Biosfera da Serra do Espinhaço, porção central de Minas Gerais, Brasil.

\section{MATERIAL E MÉTODOS}

O estudo foi realizado na Reserva da Biosfera da Serra do Espinhaço (RBSE), título concedido pela Unesco, em 2005, localizada na porção central de Minas Gerais, em uma área de cerca de 3.200 .000 ha, da qual $54,21 \%$ do seu território abarcam unidades de conservação, sendo 8,17 \% dessas na categoria de proteção integral (Figura 1). A região possui grande importância geológica e ecológica e por abarcar uma área muito extensa, vem sendo subdividida em análises ambientais em Porção Quadrilátero Ferrífero, a sul e o Espinhaço, a norte (PEREIRA et al., 2015) conforme Figura 1.

A RBSE possui clima do tipo Cwb (subtropical de altitude, com inverno seco e verão ameno) segundo a classificação de Köppen. Abarca parte de três grandes bacias hidrográficas: Rio Doce, do Jequitinhonha e do rio São Francisco (PEREIRA et al., 2015). Quanto a biogeografia, encontra-se inserida nos biomas Cerrado, a oeste, e Mata Atlântica, a leste e sul, além do contato, na porção norte, com o bioma Caatinga. O endemismo de espécies florísticas e faunísticas é marcante nesse ambiente, formando ecossistemas bastante frágeis e de baixa resistência, visto que abriga grande parte da flora ameaçada de extinção no estado de Minas Gerais (ANDRADE et al., 2015; PEREIRA et al., 2015).

A RBSE se destaca em relação a biodiversidade e, neste sentido, possui inúmeras unidades de conservação de proteção integral, nas categorias de Monumento Natural (MONA), Parque Municipal (PM), Parque Estadual (PE), Parque Nacional (PARNA), Estação Ecológica (ESEC) e Reserva Biológica (REBIO) (Figura 1).

No que concerne à metodologia, o levantamento das informações sobre os focos de calor na RBSE foi realizado a partir de dados vetoriais disponibilizadas no banco de dados do Instituto Nacional de Pesquisas Espaciais (INPE), sendo utilizado o satélite referência AQUA_M-T, sensor MODIS Moderate Resolution Imaging Spectroradiometer), com pixel de $1 \mathrm{~km}$. O estudo compreendeu a sobreposição dos dados vetoriais com os registros dos focos de calor para todos os dias dos anos de 2000, 2005, 2010, 2015 e 2017.

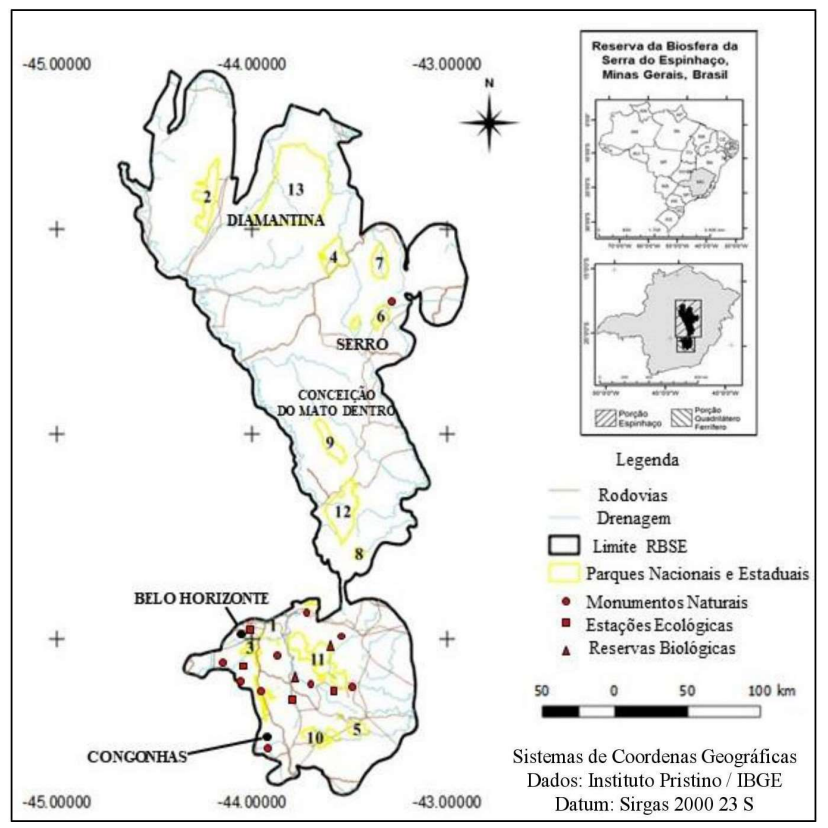

Figura 1. Localização da Reserva da Biosfera da Serra do Espinhaço, Minas Gerais, com demarcação de unidades de conservação de proteção integral e identificação para PE e PARNA. PE: 1. Baleia; 2. Serra do Cabral; 3. Serra do Rola Moça; 4. Biribiri; 5. Itacolomi; 6. Pico do Itambé; 7. Rio Preto; 8. Mata do Limoeiro; 9. Serra do Intendente; 10. Serra do Ouro Branco. PARNA: 11. Serra da Gandarela; 12. Serra do Cipó; 13. Sempre Vivas.

Figure 1. Localization of the Espinhaço Range Biosphere Reserve, Minas Gerais, with units of integral protection demarcation and identification for state and national parks. State parks: 1 . Baleia; 2. Serra do Cabral; 3. Serra do Rola Moça; 4. Biribiri; 5. Itacolomi; 6. Pico do Itambé; 7. Rio Preto; 8. Mata do Limoeiro; 9. Serra do Intendente; 10. Serra do Ouro Branco. National Parks: 11. Serra da Gandarela; 12. Serra do Cipó; 13. Sempre Vivas.

O processamento foi realizado pelo software QGIS 2.18.16, a partir da validação topológica das imagens, que posteriormente foram sobrepostas usando os registros diários totais dos focos de calor em formato vetorial (shapefile) para cada ano estudado. Diante disso, a seleção da região de interesse (Clip) foi realizada, tendo por base os limites disponibilizados em formato vetorial, com escala 1:100.000, extraídas do banco de dados do Instituto Pristino (INSTITUTO PRISTINO, 2018).

Após a extração e geração das imagens preliminares, foi realizada a interpolação e categorização dos registros pontuais dos focos, calculando a densidade por meio do estimador de Kernel segundo Equação 1:

$$
\lambda_{\tau}(\mathrm{S})=\sum_{\mathrm{i}=1}^{\mathrm{n}} \frac{1}{\tau^{2}} \mathrm{~K}\left(\frac{\left(\mathrm{S}-\mathrm{S}_{\mathrm{i}}\right)}{\tau}\right)
$$

(Equação 1)

em que: $\mathrm{n}=$ contagem pontos amostrais (eventos); $\tau=$ raio que determina grau de suavização; $\mathrm{K}=$ função de estimação de Kernel; $\mathrm{S}=$ localização geral da superfície com o valor proporcional à intensidade dos eventos por unidade de área; $\mathrm{S}_{\mathrm{i}}=$ localização inicial da superfície com o valor proporcional à intensidade dos eventos por unidade de área.

Interpolou-se valores de intensidade centrados em cada célula, inseridas em grades, considerando a função simétrica, utilizando-se os pontos situados até certa distância do centro 
de cada célula (BARBOSA et al., 2014). Diante da análise, as densidades dos focos de calor foram classificadas em cinco níveis, de acordo com os limites do gradiente de focos, de modo a obter-se níveis individuais numéricos: muito baixa (100 -191 focos por $\mathrm{km}^{2}$ ), baixa (192 - 254 focos por $\left.\mathrm{km}^{2}\right)$, média (255 - 382 focos por $\left.\mathrm{km}^{2}\right)$, alta $\left(383-763\right.$ focos por $\left.\mathrm{km}^{2}\right)$ e muito alta $\left(764-1185\right.$ focos por $\left.\mathrm{km}^{2}\right)$.

\section{RESULTADOS}

Os mapas gerados de incidência dos focos de calor por meio do estimador de densidade de Kernel para a RBSE são apresentados na Figura 2.
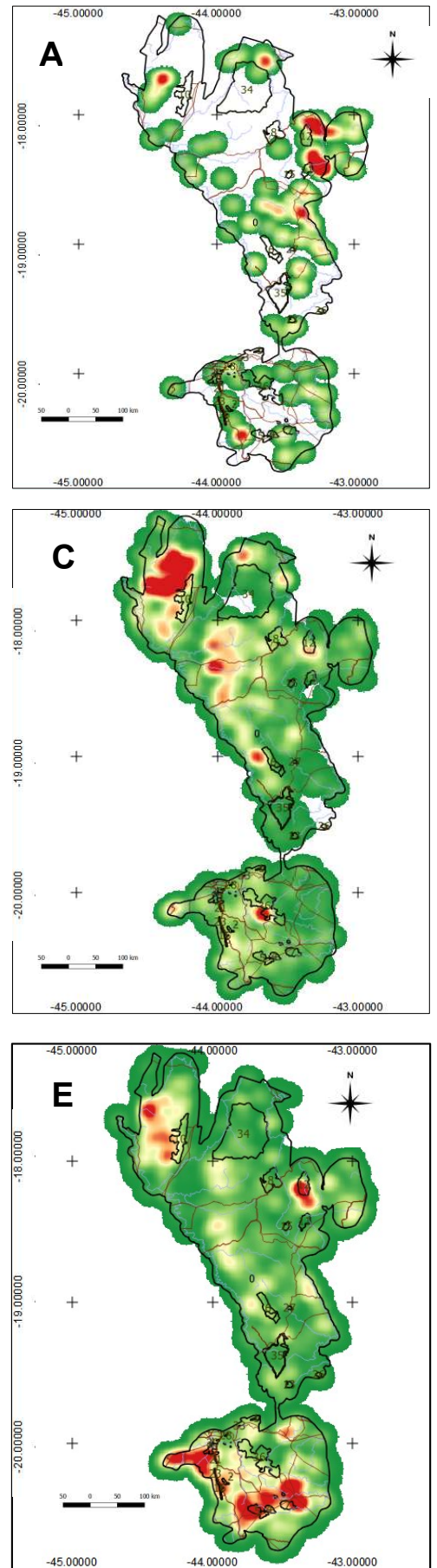

Figura 2. Análise espacial e temporal de focos de calor para a Reserva da Biosfera da Serra do Espinhaço: A) Ano de 2000; B) 2005; C) 2010; D) 2015 e E) 2017.

Figure2. Spatial and temporal analysis of heat sources for the Espinhaço Range Biosphere Reserve: A) Year 2000; B) 2005; C) 2010; D) 2015 and E) 2017 .

Nativa, Sinop, v. 7, n. 3, p. 256-261, mailjun. 2019.
Pelo mapa temático, referente ao ano de 2000 (Figura 2A), quantificou-se áreas da classe muito alta de 7.673,75 ha dentro do território da área de estudo. É possível observar menor intensidade dos focos na região sul, porção Quadrilátero Ferrífero, caracterizados pelas classes baixa e muito baixa, com exceção na região sudoeste, próximo às imediações do município de Congonhas. As classes muito alta e alta ocorrem na região Nordeste da Porção Espinhaço, nas proximidades dos municípios de Serro, Conceição do Mato Dentro e em área do PE do Itambé, assim como no norte da região do município de Diamantina, em área do PARNA Sempre Vivas e a noroeste, imediações do PE Serra do Cabral (Figura 1).
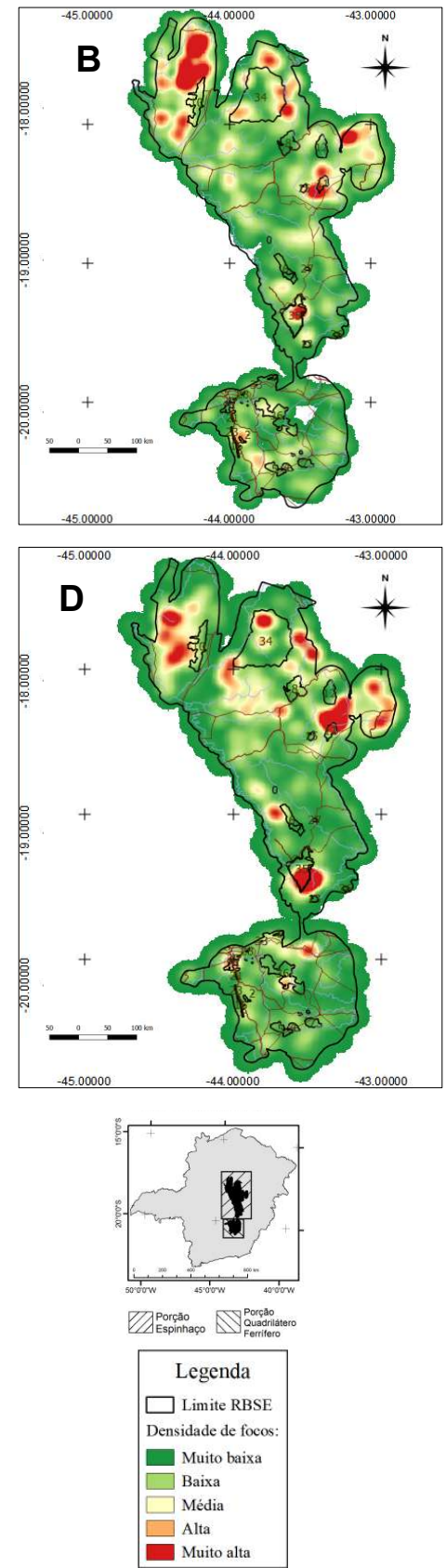
Datum SIRGAS 2000 - Zona 23S

Fonte: Instituto Pristino
Sistema de Coordenadas Geodésicas 
No ano de 2005 houve aumento significativo de focos de calor. Quantificou-se uma abrangência correspondente a 23.035,47 ha da classe muito alta para a área de estudo. A concentração das classes alta e muito alta é significativa ao Norte e Nordeste da reserva (Figura 2B), incidentes no PARNA das Sempre-Vivas, PE do Pico do Itambé e PE do Rio Preto (Figura 1).

Em 2010 a classe muito alta abrangeu 11.799,36 ha, sendo a incidência das classes alta e muito alta na região central e sul da Porção Espinhaço (Figura 2C), abrangendo área do PARNA da Serra do Cipó e noroeste, em área do PE Serra do Cabral e adjacências, ambas na Porção Espinhaço (Figura 1).

Pela análise de 2015, quantificou-se 29.059,27 ha, apresentando uma dispersão dos focos de calor semelhante ao ano de 2010. Entretanto, é nítido o aumento do raio desses focos pertencentes as classes alta e muito alta (Figura 2D). Além disso, na porção Quadrilátero Ferrífero é perceptível a distribuição das classes alta e muito alta, incidentes sobre o PE Serra do Ouro Branco, PE do Rola Moça e região da Serra do Curral (zona sul de Belo Horizonte) (Figura 1). É alarmante a consistência de classes alta e muito alta na região do PARNA Serra do Cipó (Figura 1), principalmente quando comparado aos anos anteriores.

Já em 2017 (Figura 2E) a análise indica variações bem discriminadas na distribuição espacial dos focos, abrangendo o noroeste, nordeste e sul da RBSE, havendo, em todas elas, áreas de campos rupestres, sendo mensurado 26.950,77 ha. Pela figura 2D pode-se observar um aumento significativo em termos de distribuição espacial e intensidade da densidade dos focos para a Porção Quadrilátero Ferrífero, parâmetros que servem de alerta para o monitoramento quanto aos riscos de focos de calor nessas áreas, principalmente devido ao número de unidade de conservação presentes na região.

Em relação as áreas com incidência da classe muito alta essas representam extensões com percentual significativo no território da RBSE (Figura 3).

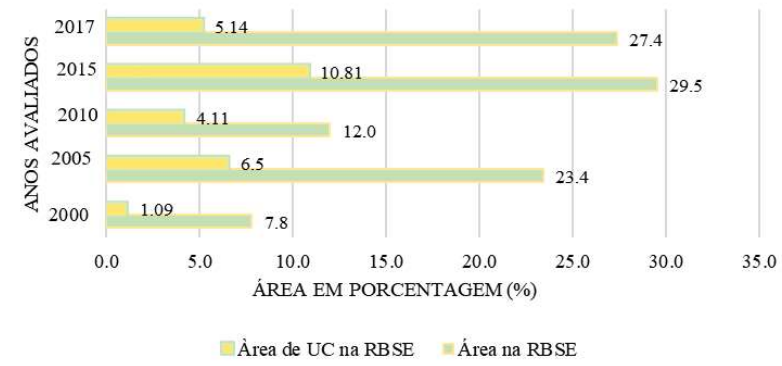

Figura 3. Porcentagem representativa de área no contexto da Reserva da Biosfera da Serra do Espinhaço com incidência de focos de calor da classe muito alta.

Figure 3. Percentage representative of area in the context of the Serra of Espinhaço Biosphere Reserve with incidence of heat outbreaks in the very high class.

\section{DISCUSSÃO}

Diante das análises, pôde-se demonstrar a representação significativa da distribuição e concentração dos focos de calor nos sítios que compõem a RBSE, levando a percepção das simulações ao longo dos anos, corroborando com os registros de incêndios florestais para as áreas com densidade alta e muito alta de focos de calor, encontrados em Andrade et al. (2015). Após o tratamento e interpretação dos dados constatou-se a espacialização dos focos de calor em relação à região estudada, levando a percepção de expressivas densidades em grande parte dos Monumentos Naturais, Parques Municipais, Parques Estaduais e Parques Nacionais, Estações Ecológicas e Reservas Biológicas, que constituem a RBSE. Nota-se pelos mapas apresentados que ao longo dos anos as áreas classificadas foram reincidentes quanto a registro da densidade de focos, principalmente, para as áreas com densidades alta e muito alta, sendo esses focos bastante dispersos em toda a RBSE.

Entre 2000 e 2005 (Figura 2A e 2B), verificou-se uma tendência crescente quanto a quantidade e distribuição espacial dos focos. Dados de precipitação do ano de 2005 constituem um fator que pode ter influenciado a acentuação de focos entre 2000 e 2005, (Figura 4) em conformidade com o trabalho de Silva (2014) que apresentou, para a série histórica 2000 - 2005, os menores valores de precipitação durante esses anos para a área que corresponde a RBSE no estado mineiro.

Além da precipitação, foi registrado para o mesmo ano temperaturas médias compensadas entre 24 e $28^{\circ} \mathrm{C}$ e umidade relativa do ar compensada de 64 a $76 \%$, conforme apontam os registros do INMET (2018). Com Figura 4. Precipitação anual média de 2005 para a Reserva da Biosfera da Serra do Espinhaço. Isso, prediz-se que os fatores meteorológicos proporcionaram condições que favoreceram a ocorrência de incêndios. A maioria dos focos detectados estão associados às condições de seca demonstradas pelos dados supracitados, além disso os apontamentos da literatura constituem a hipótese de que os demais sejam de origem antrópica (ABREU; SOUZA, 2016).

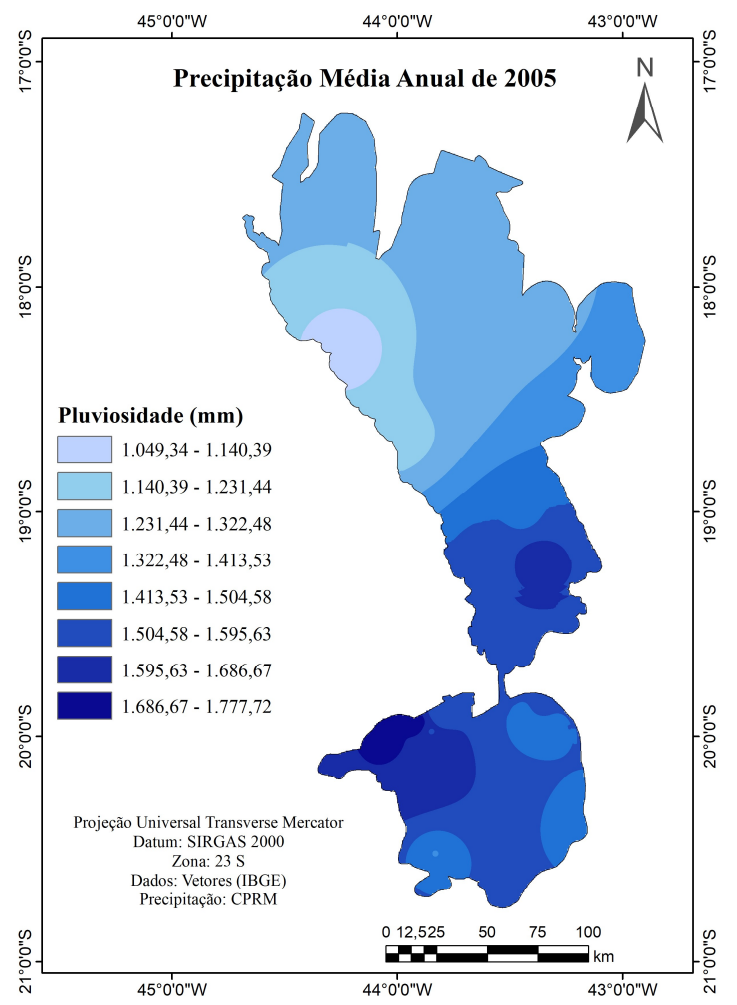

Figura 4. Precipitação média anual em 2005 na Reserva da Biosfera da Serra do Espinhaço, MG, Brasil.

Figure 4. Mean annual precipitation of 2005 to the saw Ridge Biosphere Reserve, MG, Brazil.

A análise para o ano de 2010 indica a diminuição em área correspondente a classe muito alta, em toda a área da RBSE 
(Figura 2C). Contudo, destaca-se a reincidência de densidades acentuadas a noroeste, sobre os limites do PE Serra do Cabral. A nordeste, evidencia-se uma diminuição de registros no que concerne as classes alta e muito alta (Figura 2C) quando comparado ao ano de 2005 (Figura 2B) para essa região. Valida-se esses resultados para os anos de 2010, onde as regiões demonstradas correspondem as áreas mais afetados por incêndios florestais na unidade de conservação mineira (SOARES et al., 2019). Além disso, já é explícito na comparação entre os anos 2009 e 2010 um aumento de $350 \%$ das ocorrências de focos de incêndios no Cerrado, período esse que se engloba dentro dos intervalos analisados (PEREIRA et al., 2004). Por possuir a maior parte de sua extensão dentro do bioma Cerrado, a RBSE é uma área com grande propensão e que tem apresentado números acentuados de registros de incêndios florestais (ANDRADE et al., 2015).

Transformações decorrentes dos efeitos do fogo aos recursos naturais já são evidenciadas ao analisar o uso e ocupação do solo entre 1991 e 2011 percebe-se em área de parque, como no caso no PE do Biribiri, Diamantina, uma tendência de estabilização da Formação Campestre e um decréscimo da classe Formação Savânica/Florestal Associada, sendo esta diminuição condicionada ao tempo necessário a sua regeneração em áreas onde foram constatadas a recorrência de incêndios florestais (MORAIS et al., 2016).

Como observado nos dados obtidos neste trabalho e em estudos semelhantes, os focos de calor encontrados nas classes alta e muito alta demonstram que a ferramenta pode indicar incêndios florestais. A forte pressão do fogo, principalmente vinculado à época seca do ano podem indicar grandes incêndios, mais intensos e prolongados. Machado Neto et al. (2017) descrevem que a o aumento dos incêndios nas maiores classes de focos evidenciam a necessidade de melhorias na proteção, pois indica uma deficiência nas ações de detecção, mobilização, deslocamento e combate ao fogo.

Por toda a área da reserva, estão dispersas e significativas manchas que indicam as densidades das classes média, baixa e muito baixa. Segundo Magalhães et al. (2011), quanto maior a porcentagem de focos nessas classes, se torna maior a probabilidade de eficiência do combate, pois a distribuição dos incêndios por classe de tamanho é diretamente proporcional a efetividade das ações de controle em uma determinada área.

No ano de 2015 (Figura 2D) foi significativo o aumento em área na classe muito alta a noroeste, nordeste, norte e centro-oeste, despontando-se no presente estudo, o ano com maior área com indicação de incêndios florestais. Neste mesmo sentido, o relatório de Andrade et al. (2015) também aponta para o ano de 2015 o aumento do número de focos de calor e de queimadas. Além disso, dados apresentados entre os anos de 2005 a 2015 no presente relatório, confirmam a sensibilidade da RBSE quanto a presença dos focos de calor que coadunem com às áreas observadas neste estudo.

A maior parte dos incêndios florestais que ocorre na RBSE, tem como provável causa as queimas dos campos, prática popular utilizada para renovação das pastagens. Tornase importante mostrar um exemplo de área que compreende o PARNA da Serra do Cipó (Figura 1), que para os mapas de 2000, 2010 e 2017 apresentam classe muito baixa referente a densidade de foco de calor (Figura 2A, 2C e 2E). Ranieri et al. (2012) afirmam que tal área limita o parque na forma linhas de cumeada de serra, e o acesso ao parque requer horas de caminhada, o que torna tanto fiscalização quanto combate ao incêndio bastante dificultado, evidenciando que a queima de campos tem tido menor ocorrência nessas proximidades fator desejável quando considerada a operacionalidade dentro do PARNA, diferentemente dos anos de 2005 e 2015 (Figura 2B e 2D).

De forma geral, no que concerne à RBSE, área de campo rupestre, focos de calor são preocupantes, uma vez que compreendem fitofisionomias com alto grau de endemismo e riqueza de espécies onde existem interesses minerários, crescimento urbano e que sofre com incêndios florestais nos altiplanos da Reserva da Biosfera.

A estimativa realizada pela função de Densidade de Kernel de acordo com as validações inerentes ao histórico da área, apresentou a capacidade eficiente de indicar a distribuição e intensidade dos focos, podendo ser uma interessante ferramenta para norteamento de atividade de prevenção e fiscalização.

\section{CONCLUSÕES}

Os resultados obtidos nesse trabalho indicam a eficiência do método de densidade de Kernel na espacialização e distribuição de focos de calor na RBSE para os anos analisados, corroborando com os registros de incêndios florestais em áreas que obtiveram incidência nas classes alta e muito alta.

As ferramentas SIG contribuíram para a identificação das áreas que, com a sobreposição dos registros de focos de calor, indicam que parte significativa dos focos ocorreram em áreas de unidades de conservação de proteção integral, comprometendo a manutenção da biodiversidade e a preservação dessas unidades. Presume-se por meio da análise do histórico das áreas que apresentaram maiores incidências nesse estudo que variações climáticas influenciam fortemente a ocorrência de incêndios, seguida por ações antrópicas e elementos da paisagem que caracterizam a reserva.

Diante disso, este trabalho constitui-se como subsídio para o monitoramento ambiental e ferramenta para estudos futuros da dinâmica e distribuição de focos de calor, representando uma ferramenta auxiliar na compreensão de fatores e comportamento dos mesmos nesses ambientes.

Entende-se que mais estudos podem ser conduzidos e validados com o uso das técnicas de geoprocessamento relacionada a incidências de focos de calor e incêndios florestais, sendo de grande aplicabilidade para a conservação dos recursos naturais, bem como a utilização desses conhecimentos para o monitoramento, elaboração de mapas de risco e definição de estratégias para a prevenção e amenização de impactos ambientais.

\section{AGRADECIMENTOS}

O presente trabalho foi realizado com apoio da Coordenação de Aperfeiçoamento de Pessoal de Nível Superior - Brasil (CAPES) - Código de Financiamento 001.

\section{REFERÊNCIAS}

ABREU, F. de A.; SOUZA, J. do S. Dinâmica Espaçotemporal de Focos de Calor em Duas Terras Indígenas do Estado de Mato Grosso: uma Abordagem Geoespacial sobre a Dinâmica do Uso do Fogo por Xavantes e Bororos. Revista Floresta e Ambiente, Seropédica, RJ, v. 23, n. 1, 2016. DOI: http://dx.doi.org/10.1590/2179-8087.041813

ANDRADE, M. A.; MARTINS, C. S.; DOMINGUES, S. A. (Org.). Reserva da Biosfera da Serra do Espinhaço 
Primeira Revisão Periódica. 1. ed. Belo Horizonte: MaBUNESCO, 2015. 300 p.

BARBOSA, N. F. M.; STOSIC, B. F.; STOSIC, T.; LOPES P. M.; MOURA, G. B. de A.; MELO, J. S. P. Kernel smoothing dos dados de chuva no Nordeste. Revista Brasileira de Engenharia Agrícola e Ambiental, Campina Grande, v. 18, n. 7, p. 742-747, 2014. DOI: http://dx.doi.org/10.1590/S1415-43662014000700011

INMET_INSTITUTO NACIONAL DE METEOROLOGIA. Banco de dados meteorológicos para ensino e pesquisa. Disponível em: $<$ http://www.inmet.gov.br/portal/index.php?r=bdmep/bd mep>. Acesso em 03 abr 2018.

INSTITUTO PRISTINO. Atlas Digital Geoambiental. Disponível em $<$ https://www.institutopristino.org.br/atlas/>. Acesso em 03 abr 2018

MACHADO NETO, A. de P.; BATISTA, A. C.; BIONDI, D.; SOARES, R. V.; BATISTA, A. P. B. Incêndios florestais no Parque Nacional da Chapada dos Guimarães-MT entre 2005 e 2014. Revista Nativa, Sinop, MT, v.5, n.5, p.355361, 2017. DOI: http://dx.doi.org/10.5935/2318 7670.v05n05a09

MAGALHÃES, S. R. de; LIMA, G. S.; RIBEIRO, G. A Avaliação do combate aos incêndios florestais no Parque Nacional da Serra da Canastra. Revista Floresta e Ambiente, Seropédica, v. 18, n. 1, p. 80-86, 2011. DOI: http://dx.doi.org/10.4322/floram.2011.025

MORAIS, M. S.; GONTIJO. B.M.; PIUZANA, D. Análise temporal do uso e ocupação do terreno do Parque Estadual do Biribiri e de sua Zona de Amortecimento, município de Diamantina, Minas Gerais. Revista Caderno de Geografia, Belo Horizonte, v. 26, n. 46, p. 362-381, 2016. DOI: 2962.2016v26n46p362

PEREIRA, C. A.; FIDLER, N. C.; MEDEIROS, M. B. Análise de ações de prevenção de combate aos incêndios florestais em unidades de conservação do cerrado. Revista Floresta, Curitiba, PR, v. 34, n. 2, p. 95-100, 2004. DOI: http://dx.doi.org/10.5380/rf.v34i2.2378

PEREIRA, E. O.; GONTIJO, B. M.; ABREU, L. G. A. C. As ecorregiões da reserva da biosfera da serra do espinhaço: elementos para o fortalecimento da conservação da biodiversidade. Revista Caderno de Geografia, Belo Horizonte, v. 25 , n. 43, p. 18-33, 2015. DOI: http://dx.doi.org/10.5752/P.2318-2962.2015v25n43p18

RANIERI, B. D.; NEGREIROS, D.; LANA, T. C.; PEZZINI, F.F.; FERNANDES, G. W. Fenologia reprodutiva, sazonalidade e germinação de Kielmeyera regalis Saddi (Clusiaceae), espécie endêmica dos campos rupestres da Cadeia do Espinhaço, Brasil. Revista Acta Botânica Brasileira, Feira de Santana, v. 26, n.3, p. 632-641, 2012. DOI: 33062012000300012

RIBEIRO, M. N.; SANCHEZ, M.; PEDRONI, F.; PEIXOTO, K. DA S. Fogo e dinâmica da comunidade lenhosa em cerrado sentido restrito, Barra do Garças, Mato Grosso. Revista Acta Botanica Brasilica, Feira de Santana, v. 26 n. 1, p. 203-217, 2012. DOI: http://dx.doi.org/10.1590/S0102-33062012000100020

RODRÍGUEZ, M. P. R.; SOARES, R. V.; BATISTA, A. C.; TETTO, A. F.; BECERRA, L. W. M. Comparação entre o Perfil dos Incêndios Florestais de Monte Alegre, Brasil, e de Pinar Del Río, Cuba. Revista Floresta, Curitiba, v. 43 n. $2, \quad$ p. 231-240, 2013. DOI: http://dx.doi.org/10.5380/rf.v43i2.27650

SILVA, E. D. da. Estudo da precipitação no estado de Minas Gerais - MG. Revista Brasileira de Climatologia, v. 13 , n. $9, \quad$ p. 120-136, 2014. DOI: http://dx.doi.org/10.5380/abclima.v13i0.33345

SOARES, T. B. O.; GONTIJO, B. M.; PEREIRA, G. Análise dos focos de incêndio no período de 2000 a $2014 \mathrm{em}$ unidades de conservação na Reserva da Biosfera do Espinhaço. Disponível em: $<$ http://observatoriogeograficoamericalatina.org.mx/egall 5/Procesosambientales/Proteccioncivil/09.pdf>. Acesso em: 16 abr 2019

TEBALDI, A. L. C.; FIEDLER, N. C.; JUVANHOL, R. S.; DIAS, H. M. Ações de Prevenção e Combate aos Incêndios Florestais nas Unidades de Conservação Estaduais do Espírito Santo. Revista Floresta e Ambiente, Seropédica, v. 20, n. 4, p. 538-549, 2013. DOI: http://dx.doi.org/10.4322/floram.2013.036

TORRES, F. T. P.; RIBEIRO, G. A.; MARTINS S. V.; LIMA, G. S. Mapeamento da suscetibilidade a ocorrências de incêndios em vegetação na área urbana de Ubá - MG. Revista Árvore, Viçosa, v. 38, n. 5, p. 811-817, 2014. DOI: $\quad$ http://dx.doi.org/10.1590/S010067622014000500005

TORRES, F. T. P.; ROQUE, M. P. B.; LIMA, G. S.; MARTINS, S. V.; FARIA, A. L. L. Mapeamento do Risco de Incêndios Florestais Utilizando Técnicas de Geoprocessamento. Revista Floresta e Ambiente, Seropédica, v. 24, p 1-10, 2017. DOI: http://dx.doi.org/10.1590/2179-8087.025615

VIJAYAKUMAR, D. B. I. P.; RAULIER, F.; BERNIER, P. Y.; GAUTHIER, S.; BERGERON, Y.; POTHIER, D. Lengthening the historical records of fire history over large areas of boreal forest in eastern Canada using empirical relationships. Forest Ecology and Management, Amsterdam, v. 347, p. 30-39, 2015. DOI: https://dx.doi. org/10.1016/j.foreco.2015.03.011 